\title{
CONCEPTUAL AND THEORETICAL DESIGN MODELLING AND SIMULATION ANALYSIS OF A TURBOFAN ENGINE AT OPTIMAL PERFORMANCE
}

\author{
P. B. SOB
}

Department of Mechanical Engineering, Faculty of Engineering and Technology, Vaal University of Technology,

Vanderbijlpark 1900, Private Bag X021, South Africa

\begin{abstract}
In the current study, a novel design of a turbofan engine was theoretically conceptualized, model and simulated for optimal performance during operation. This was achieved byusing Autodesk Inventor software and Autodesk CFD software. The study also employed the tool of finite element analysis in modelling performance safety during optimal operation. A new turbofan engine was designed by making use of proper tolerance analysis and performance check in the system design of the turbofan engine. Due to this, several fundamental numerical analysis and simulation was done on blades and geometries in order to optimize the system performance at better efficiency during operation at different cycles of fluid properties and flow station. To achieve this, the different components of the system aerodynamic design parameters, the sizing of the system component and the system efficiency were computed and simulated by using the tool of CFD and taken into consideration many aspects of the turbomachinery operating components that were modelled at optimal and satisfactory performance. A compressive design and analysis of a turbofan engine was revealed. It was also shown that, the energy content of the design system increased significantly due to varying parameters for material selection in the design system. It was also shown that material selection plays a vital role on performance, manufacturing cost and the system life cycle and efficiency during operation. Varying modelling and design analysis of fan, compressors, combustor, turbines, and nozzle were revealed by Autodesk Inventor software and Autodesk CFD software significantly impact design performance during operation. It was also revealed that a numerical analysis of the system mass flow rate on blades and inlet geometries impacts the performance of the turbofan engine and the system became more efficient during operation.
\end{abstract}

KEYWORDS: Design, Performance, Modelling, Simulation, Efficient, Turbofan Engine.

Received: Feb 08, 2021; Accepted: Feb 28, 2021; Published: Apr 01, 2021; Paper Id.: IJMPERDJUN20218

\section{INTRODUCTION}

Most of the turbofan engines being used in aircraft propulsion engines have gone several design modification processes [1-3]. Most of the design operations have been on absorbing additional energy from the system's highpressure turbine line during the operation and this energy is used to drive the fan and the system's low-pressure compressor line that are located upstream of the main compressor in the design during operation [1-5]. Most of the aircraft propulsion engine performs several vital tasks during the operation. One of the main tasks of the engine is to provide more energy (propulsive energy) to the aircraft system propeller during the operation and this is done throughout its route of operation and at the same time, the system must achieve the appropriate operating performance mode and operating efficiency [1-6]. The other main task of the design turbofan engine during operation is to provide a prime energy source for generation of electrical power that are used to power other driving components such as the hydraulic and pneumatic components [4-6]. Lastly, the design must provide sufficient air in the system and that creates a habitable environment for the crew members on board, passengers on board, 
and the system avionics equipment of the aircraft [6-9]. Therefore, the cost of the system is reasonably sustainable in terms of investment and possible incorporation to different aircraft design in terms of system safety, reliability, and cost effectiveness [4-9].

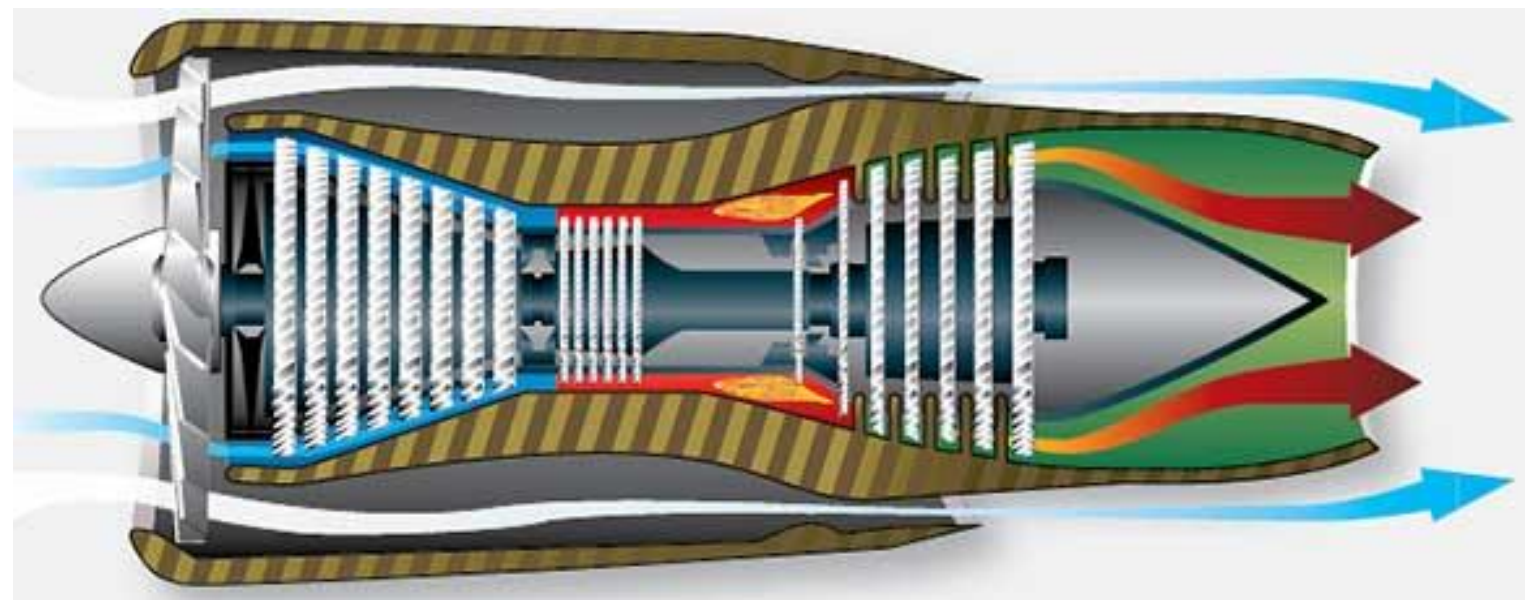

Figure 1: Turbofan Engine during Operation

The main design goal of the system is to control system performance at optimal and accurate operating efficiency that is stable and efficient during operation [1-10]. Most modern designs of turbofan engine are higher in fuel consumption and the design system is not stable and efficient in operating condition [1-8]. In the past years, researchers have focused on modelling and optimising the system performance during operating with the aim of maintaining stability at low consumption. The modelling and optimisation was done without taking into consideration the key operating variables in conceptual and theoretical design modelling for optimal performance. This resulted in the system design with several gas turbine engine models and their control systems operating variables have been very useful in technical decision making and cost optimisation process mode for testing, stable and enhance performance during operation before the final manufacturing process. This has been faced by several challenges in performance optimisation since most of the current designs of turbofan engine are not well conceptualize in theoretical design modelling and simulation [4-12]. Initially, the relevant mathematical models for optimal design consideration of the turbofan engine are modelled or built in Autodesk software and this process takes into account the limited conceptual theories and principles in empirical modelling [4-11]. After building the model without optimal conceptualization processing, it is very important to extract linearized modelling principles and is used for better design system and analysis [5-10]. This has been faced with the backdrop of several challenges and thus impacting the performance characteristic in a modern turbofan engine [5-9]. Most analytical techniques or approaches being used are common in control analysis and optimisation of design of control systems during operation. The modelling of linearization process is mostly done by using an Autodesk Inventor/CFD. The rationality in fuel flow is being used to control the system thrust has been used in earliest hydro-mechanical systems design and is a strategy used in most gas turbine engines without proper system design conceptualization and simulation process. Other control signals are often used for limiting the engine from exceeding its operating range and this is impacted by design conceptualization and design modelling [4-12]. It is therefore important to theoretically model and simulate an efficient design of a turbofan engine from empirical conceptualization. In this current study, a conceptual system is modelled by taking into consideration the relevant system input signal of the system fuel flow during operation. The relevant system output signal is modelled for optimal performance at high-pressure compressor speed of rotation during operation. The more accurate and efficient the control performance of engine thrust is achieved during operation is the primary objective 
of the gas turbine engine during operation. The design system was optimized through the relevant control variables of compressor speed during operation. The desired system performance requirements during operation were obtained for faster system response during operation without any system overshoot during modelling and optimization process.

\section{METHODOLOGY}

\section{Theoretical Consideration for Proper Conceptualization of Design Modelling and Simulation}

Most engine designs of turbofan consisted of vital component that are modelled for optimal performance as shown in Figure 2. From conceptual modelling theory and analysis, the major components that are modelled for optimal performance are: the system fan, the system High Pressure (HP) Compressor, the system Combustor, High Pressure (HP) Turbine, the system Low Pressure (LP) Turbine during operation, the system Bypass Plenum Volume during operation, the system Nozzle in the design, High Pressure (HP) Shaft in the system during operation, and Low Pressure (LP) Shaft in the system. It should be noted that the different component in the turbo-machinery system have similar fundamental theoretical models in modelling being defined from physical modelling. Most of the common equations include in the fan design, HP compressor design, HP turbine design, and LP turbine design are analysed in this study and that takes into consideration the system mass flow rate, operating temperature, and system work process.

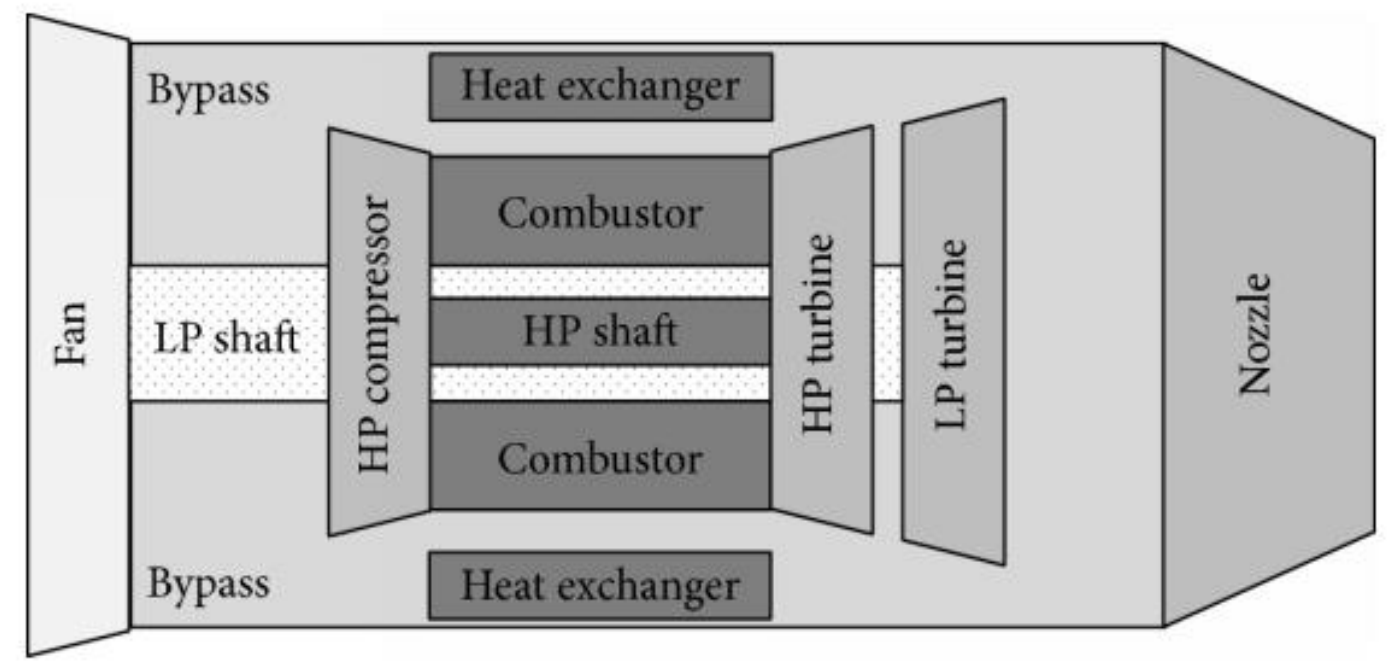

Figure 2: Key components of the Turbofan and Pressure Taking Place in Them.

The conceptual modelling in this study was based on Autodesk inventor and the simulation was done through CFD Autodesk Software. The theoretical design parameters for optimal performance were taken into consideration during modelling. The modelling process in the system includes performance mapping process, drop in pressure in the system during operation, the system plenum volume dynamics during operation, the thermal transients process in the system during operation, the chemical reactions process in the system, parallel flow paths in the system and mass flow rate in the system which is dependent on local densities of the system during operation and system pressure loses during operation and system shaft dynamics during operation. There is a more detailed analysis that descripts the different models and component being used in the designed system and this includes all the critical parameters of the system. Most high pressure (HP) turbine system receives combustor outlet mixture during operation. The power generated by the system turbine is being used to drive the system and produced the necessary torque to the High Pressure shaft during operation. This drives 
the High Pressure compressor in the system during operation. The plenum volume in the system being located between the High Pressure compressor in the system and the High Pressure turbine inlet in the system is being modelled within the High Pressure turbine line and it is used to derive the system High Pressure turbine inlet pressure during operation. The plenum volume in the system accounts for the volume of flow in the combustor during operation. The system mass flow rate during operation, entering this plenum volume is known from the system High Pressure compressor model during operation. The system outlet mass flow rate of the High Pressure turbine during operation is usually specified by the system performance mapping during operation and this is in line with the incoming and outgoing mass flow rate produced by the plenum volume of the system known as the dynamic pressure of the plenum volume during operation.

As air enters the system High Pressure turbine during operation, a secondary air stream in the system blade cooling line is added to reduce the operating temperature of the system during operation. The secondary stream in the system is fed by air in the bleed that is being removed at the exit of the High Pressure compressor during operation. During operation, the High Pressure turbine model system modelled a subsystem exists of discharge flow, which cools the HP turbine inlet as well as the system flow rate of air in the system and this continues to the Low Pressure turbine of the system. The High Pressure turbine bleed flow in the system is mixed with core air from the combustor outlet system before it finally enters the High Pressure turbine system in order to provide better cooling process during operation. Two calculations are needed in the system to determine or predict the mass flow rate in the system as well as the operating temperature in the system during operation.

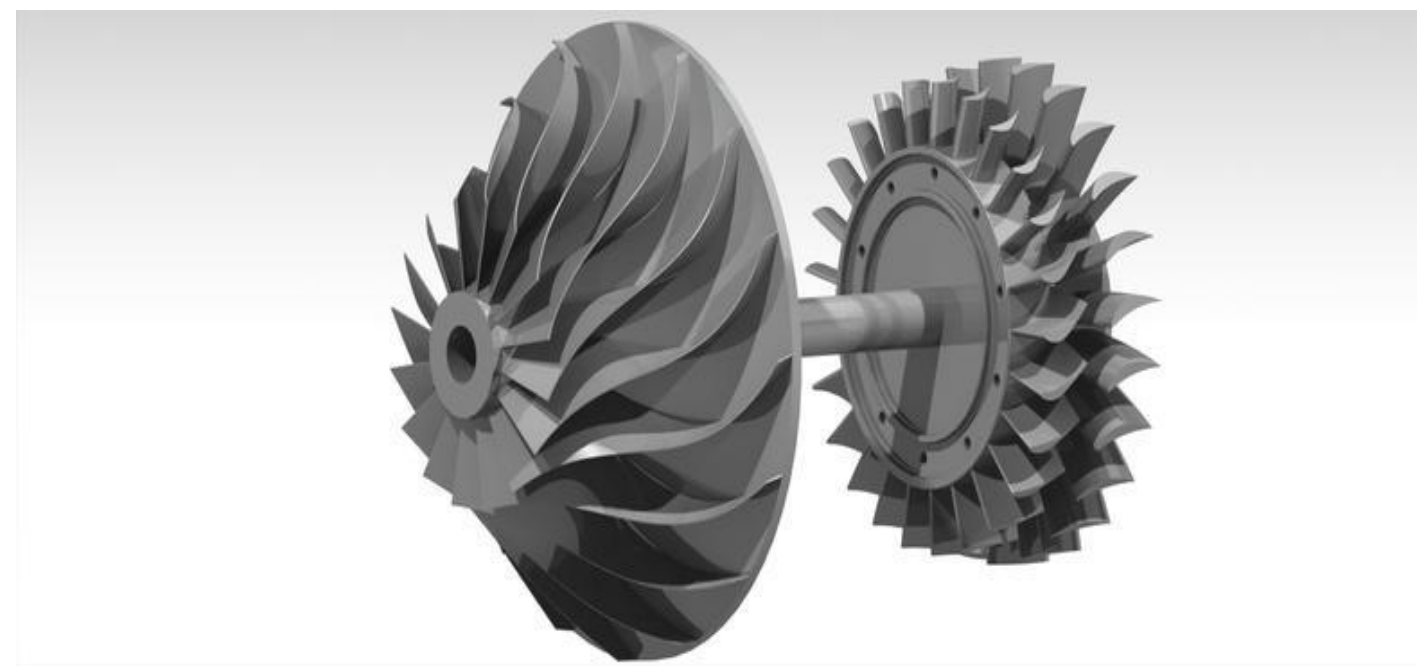

Figure 3: Turbine and Compressor Assembly on the Shaft

After the system core air exits in the high pressure turbine system during operation, the air enters the low pressure turbine system line. The operating system's low pressure turbine produces power line that drives the low pressure shaft during operation, which in turn drives the fan in the system during operation. The system inlet pressure during operation is found in a similar manner to the system inlet pressure of the high pressure turbine system during operation. The low pressure turbine bleed air mass flow rate of the system during operation is already known from the system bypass plenum during operation. The system mass inlet flow rate in the system which includes the core air from the system high pressure turbine outlet of the system as well as the system low pressure turbine bleed air during operation, and the inlet temperature are found in the system. The system bypass model of operation being determines bypass flow rate and pressure of the system during operation. The system bypass process comprised of the void space in the system around the high pressure 
compressor during operation and the combustor, the high pressure turbine, the low pressure turbine, and the shafts. The air that bypasses process and the high pressure compressor process, the combustor, the high pressure turbine, and the low pressure turbine travels through a bypass duct system and enters a mixer plenum volume at the nozzle inlet. The majority of the fan mass flow enters the bypass rather than the high pressure compressor. The pressure drop in the system across the bypass plenum volume drives the amount of mass flow in the system that bypasses the core of the engine during operation. The nozzle line is the final component in a turbofan engine flow path system. A designed converging-diverging nozzle system creates the relevant thrust needed to propel the aircraft forward during operation. The air from the low pressure turbine outlet system and the bypass plenum volume are being combined in the mixer volume before entering the nozzle during operation and within the actual nozzle in the system, two cases can exist are designed and a choked flow or nonchoked flow. To determine which case is occurring at a given time interval, a critical pressure ratio in the system is being calculated during operation. To model and determine the thrust exit velocity in the system, the system mass flow rate must be calculated.

The choked flow in the system occurs when the actual nozzle pressure ratio in the system is less than the critical pressure ratio in the system, while non-choked flow occurs for pressure ratios larger than the critical value during operation and when the nozzle model has been optimized and determined that the flow is choked during operation. The exit temperature of the system is calculated or computed, and the speed of sound in the system and exit velocity are computed during operation and when the flow is not choked in the system during operation, several terms in the system must first be derived and this including the exit Mach number of the system and the exit temperature of the system and the speed of sound at the nozzle exit of the system using the exit Mach number in the system and the exit temperature is calculated. With the exit temperature in the system known, the speed of sound at the nozzle exit is also calculated and computed as in the choked case during operation. The system velocity of air exiting the nozzle during operation can be found using the speed of sound in the system and the Mach number results in the system. The system density of air exiting the nozzle is found during optimisation. Finally, the exit mass flow of the nozzle during operation is found once the nozzle mass flow rate and exit velocity have been established during operation, for choked or non-choked flow in the system and the thrust is calculated. The system thrust being produced by the engine system during operation is based on the system mass flow entering and exiting the engine during operation as well as the pressure difference in the system between the nozzle and ambient air during operation. The system inlet mass flow rate during operation which is equivalent to the fan mass flow rate of the system during operation is already known. The inlet velocity of the system must be calculated. By using the inlet velocity of the system, the total engine thrust during operation is represented for a convergent nozzle during operation.

The system high pressure shaft used to connect the high pressure turbine and the high pressure compressor is designed. The power from the high pressure turbine line is transferred by the high pressure shaft to drive the high pressure compressor during operation. The high pressure turbine work signal represents a positive load in the system and the high pressure compressor in the system work signal represents a negative load during operation. The high pressure shaft speed is the only calculation performed in the system within the shaft model of operation and additional auxiliary loads may be added to the shaft during operation. The low pressure shaft in the system connects the low pressure turbine and the fan in the system. The power from the low pressure turbine in the system is transferred by the low pressure shaft to drive the fan system during operation. The low pressure turbine work signal represents a positive load and the fan work signal represents 
a negative load. The low pressure shaft speed is the only calculation performed within the model. The low pressure shaft has additional auxiliary loads, pumps, and generator, which are inputs to the engine model.

\section{Modelling, Designing and Simulation of the Turbofan}

The conceptual design modelling and simulation started from the fan assembly system for optimal performance by taking relevant parameters and CFD simulation assumption. The following figures are taken from the model done from the Autodesk Inventor:

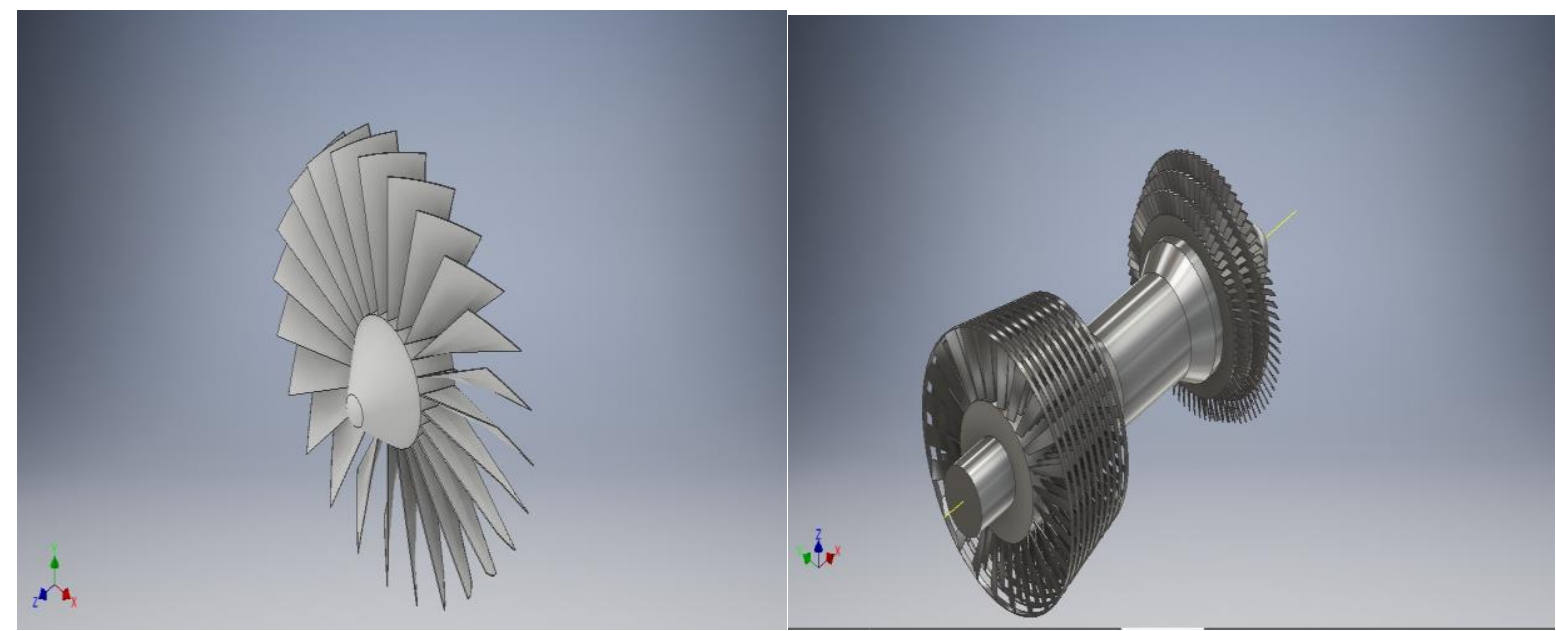

(a)

(b)

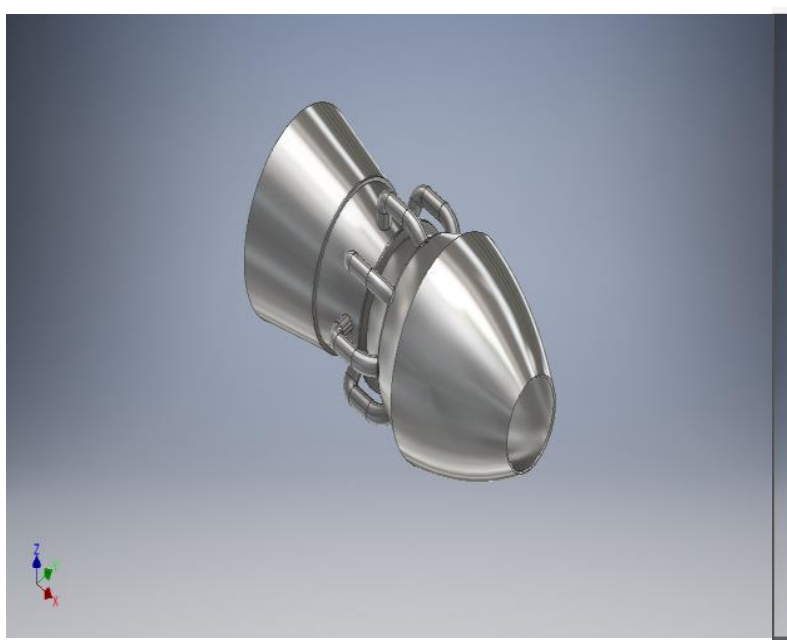

(c)

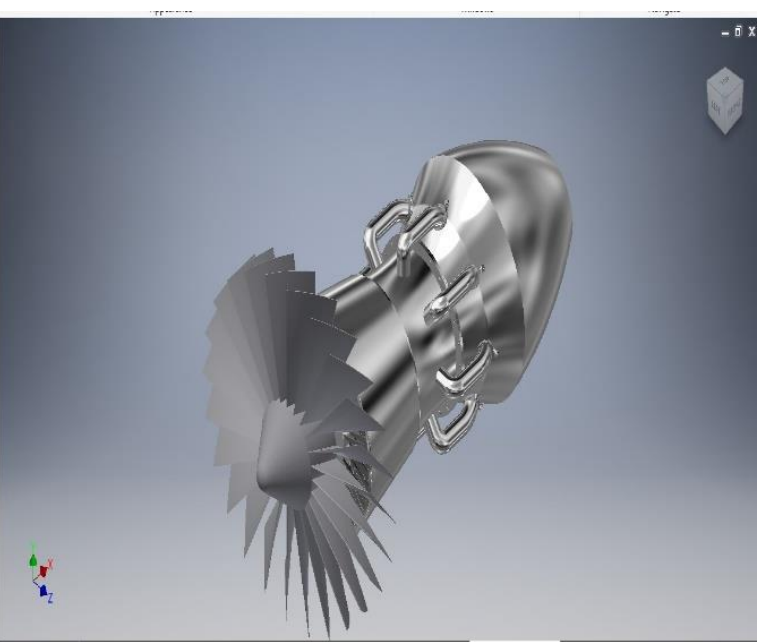

(d)

Figure 4: (a) Fan Assembly (b) Turbine and Compressor Blades Assembly (c) The Turbofan Shell with the Nozzle Assembly (D) Turbofan Assembly

\section{Simulation Result Analysis}

The simulation was done by Autodesk CFD and the relevant conceptual design parameters were taken into consideration for optimal design performance. The simulation was also done with the aid of the turbofan engine model; the conditions chosen were to test if the turbofan would run at optimal speed without any failure on material stress and strains at optimal engine speed. During simulation, the flow through the fan or mass flow rate in the system was monitored in 3-D as shown in Fig. 4. For proper conceptualization and design modelling and simulation, the following simulation step or approach was 
taken into consideration (a) Identify the $3 \mathrm{~d}$ model (b) Mesh the model. Also known as pre-processing method (c) Define analysis type, (d) Specify fluid properties \& boundary conditions (e) Selection of numerical schemes. Solvers and interpolation schemes for solution system (f) Post-process results - (pressure loss/gain, velocity \& forces). The first step in simulation was to identify the relevant 3-D model in the conceptual design and this was taken into consideration that it must be taken after 100 simulations, force wind will converge as shown in Figure 5.

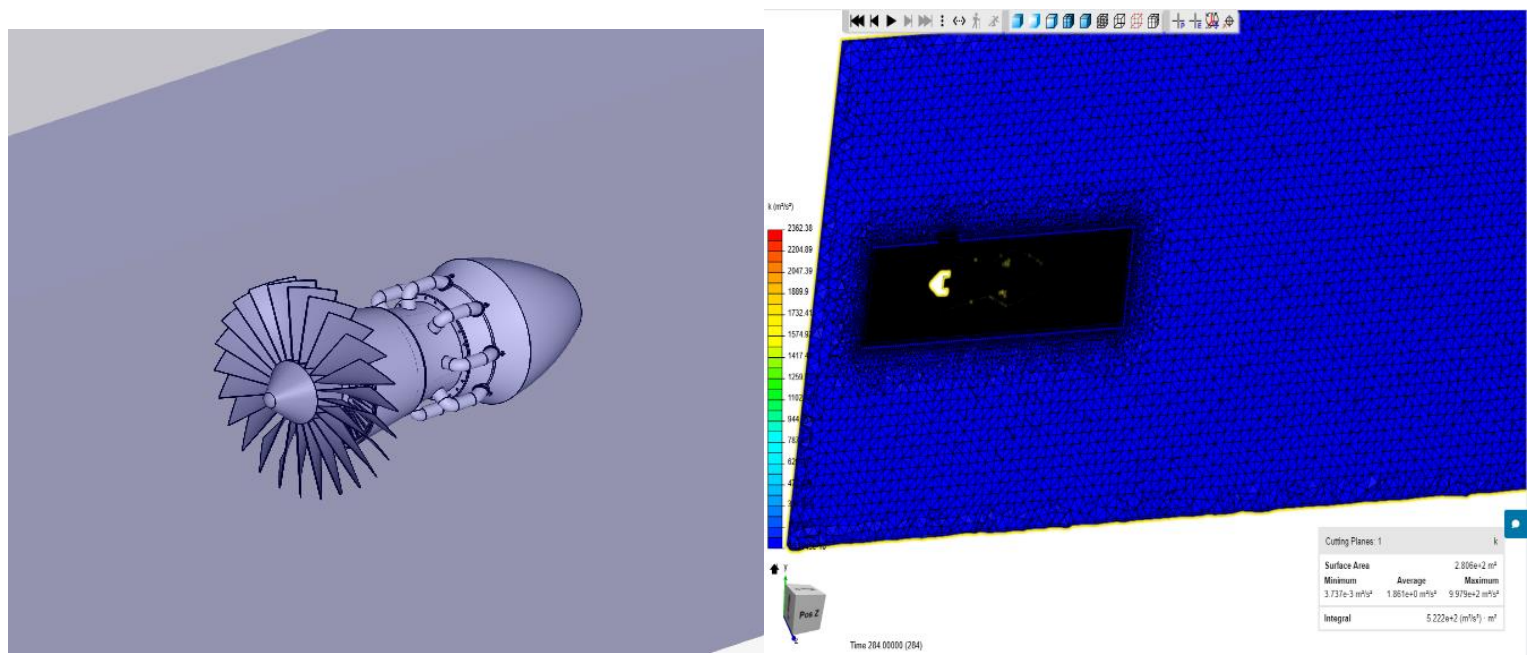

(a)

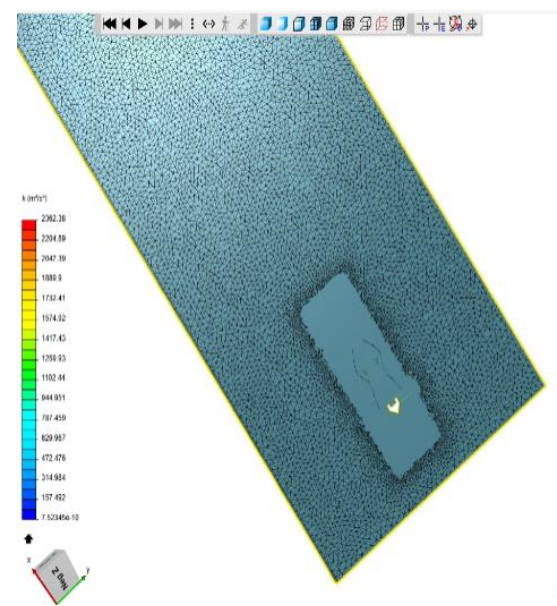

(c)

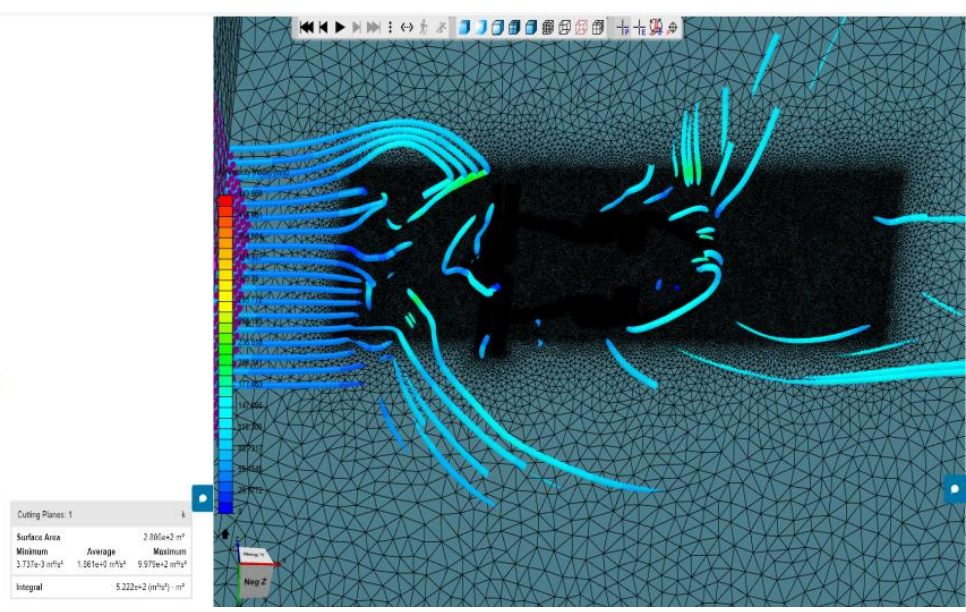

(d)

Figure 5: (a) Turbofan Assembly on CFD (b-d) Mesh Model

The model and assembly of the turbofan engine were done on Autodesk inventor and for simulation of the turbofan we had to identify the model in CFD, so that we can simulate it, the figure above is how the turbofan engine looks when we have identified it. For the simulation to be run, we had to create a flow region, which will help control the system around the turbofan engine and measure the results obtained. Figure 5(c-d) revealed meshed figures of the turbofan engine; it is necessary to mesh the model as this eliminated any foreign particles in the model before simulating it. This is the preprocessing stage of the turbofan engine as it prepares the prototype for simulation. The small shapes shown in Fig.5 (b-d) is the actual mesh being done on the turbofan. This impacts the specific fluid properties and flow analysis and system performance of the system. The main factor being affected is the incompressible fluid characteristics as the flow density of 
fluids remains constant in any fluid parcel, i.e. any infinitesimal volume of fluid moving in the flow. Incompressibility is a feature exhibited by any fluid under certain conditions. Therefore, it is proper to study the air characteristics in the system during operation as shown in Fig.6. The air viscosity model, velocity inlet boundary condition model, pressure outlet boundary condition model, symmetry boundary conditions model, wall 4 and wall 5 boundary condition model, numeric and simulation control model shown in Fig 6 (a-h).

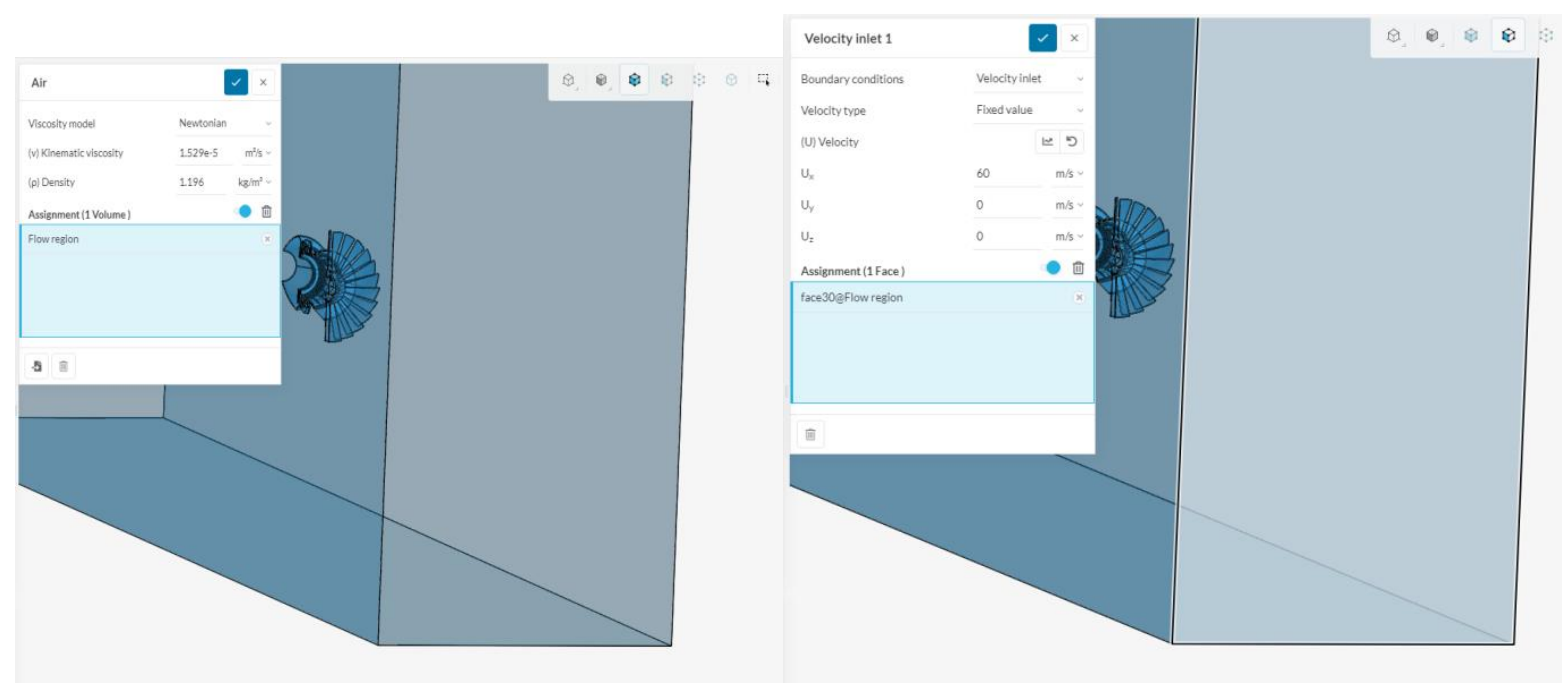

(a)

(b)

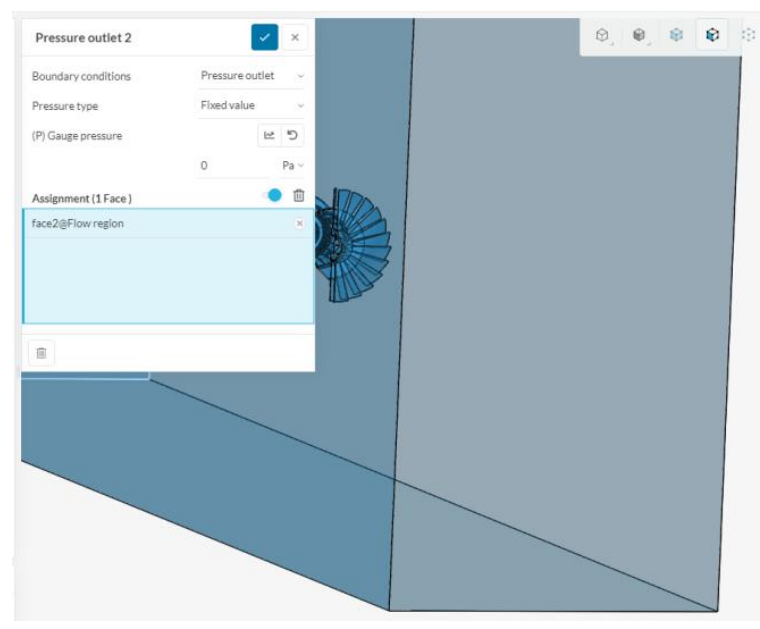

(c)

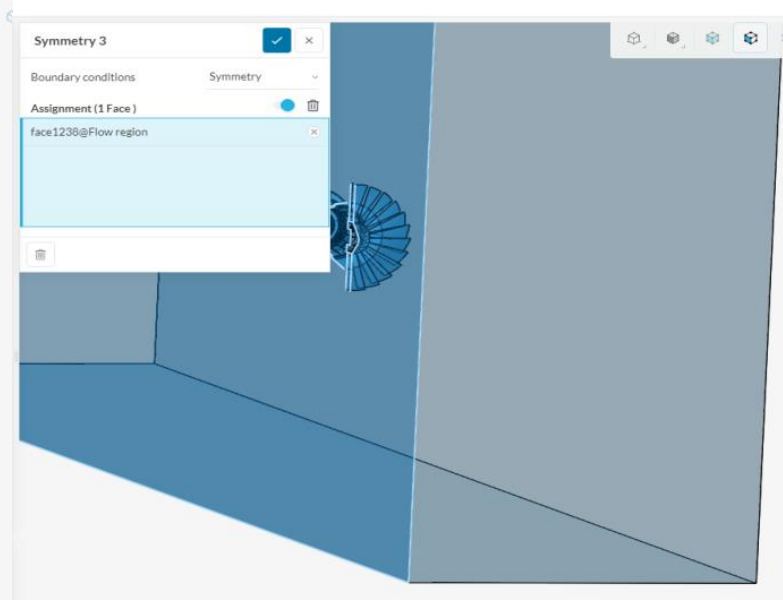

(d) 


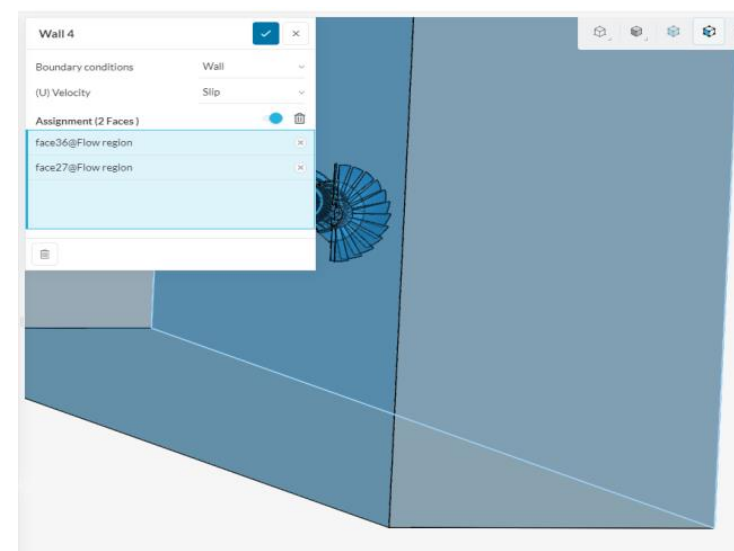

(e)

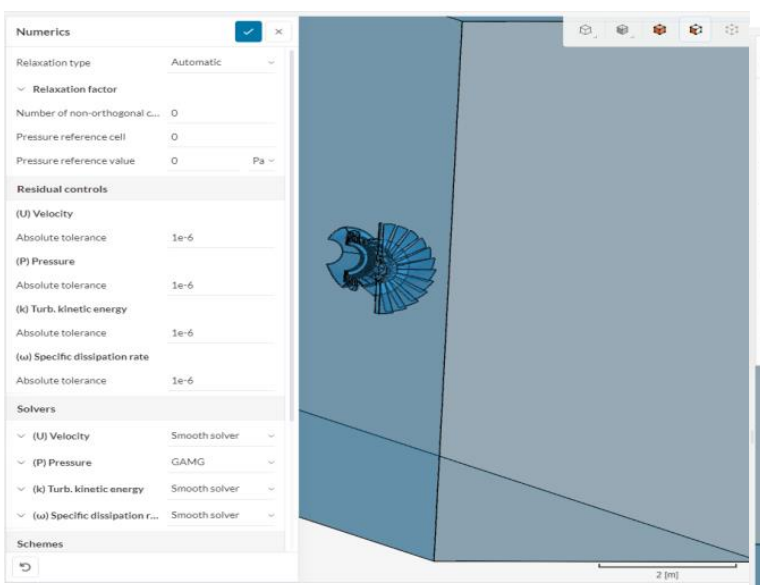

(g)

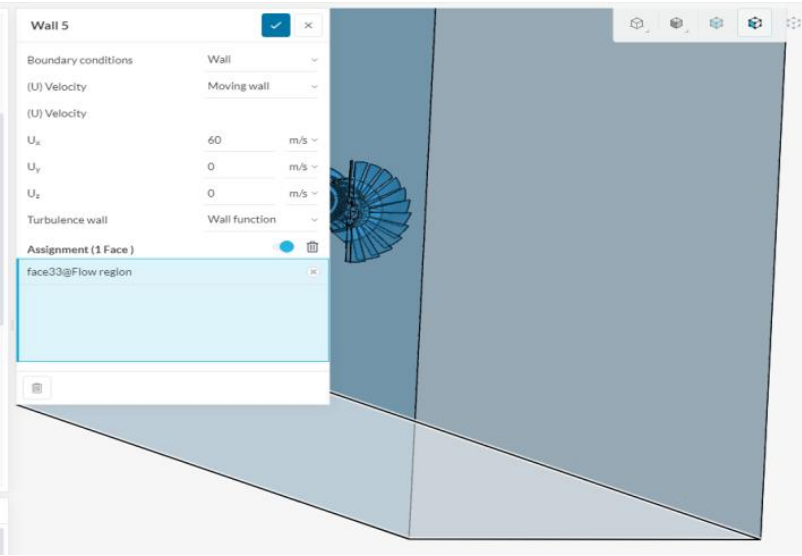

(f)

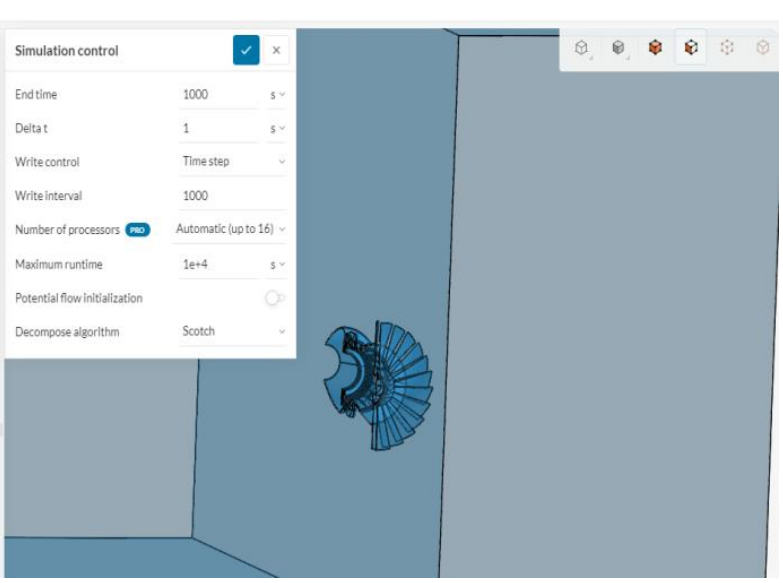

(h)

Figure 6 (A) Air Viscosity, (B) Velocity Inlet Boundary Condition Model, (C) Pressure Outlet Boundary Condition Model (D) Symmetry Boundary Conditions Model, (E) Wall 4 Boundary Condition Model, (F) Wall 5 Boundary Condition Model, (G) Numeric Model System And (H) Simulation Control Model.

Table 4.1: Initial Conditions

\begin{tabular}{|l|c|c|}
\hline \multicolumn{1}{|c|}{ Unit } & Amount & SI unit \\
\hline Gauge Pressure & 0 & $\mathrm{~Pa}$ \\
\hline Velocity & 0 & $\mathrm{~m} / \mathrm{s}$ \\
\hline Kinetic Energy & 3.75 & $\mathrm{~m} 2 / \mathrm{s} 2$ \\
\hline Dissipating rate & 3.375 & $1 / \mathrm{s} 2$ \\
\hline
\end{tabular}

The table above shows the initial conditions that we are working our simulation on, the following figures show the boundary conditions that will affect the turbofan. We choose these conditions so as to run the programme and see if the turbofan will run effectively and if so what results will it have due to the condition that it will be running at boundary conditions shown in Figure 6 (a-f). This affects the numerical and control simulated system during operation as shown in Figure $6(\mathrm{~g}-\mathrm{h})$. This is affecting the system control parameters such as force of coefficient. 


\subsection{Result Control.}

\section{Force Coefficients}

We had to put some controls in the simulation so that the result that we obtain can be analysed with ease. We had the centre of rotation, lift direction and drag direction in the $\mathrm{x}$-axes because the wind will be blowing from this direction

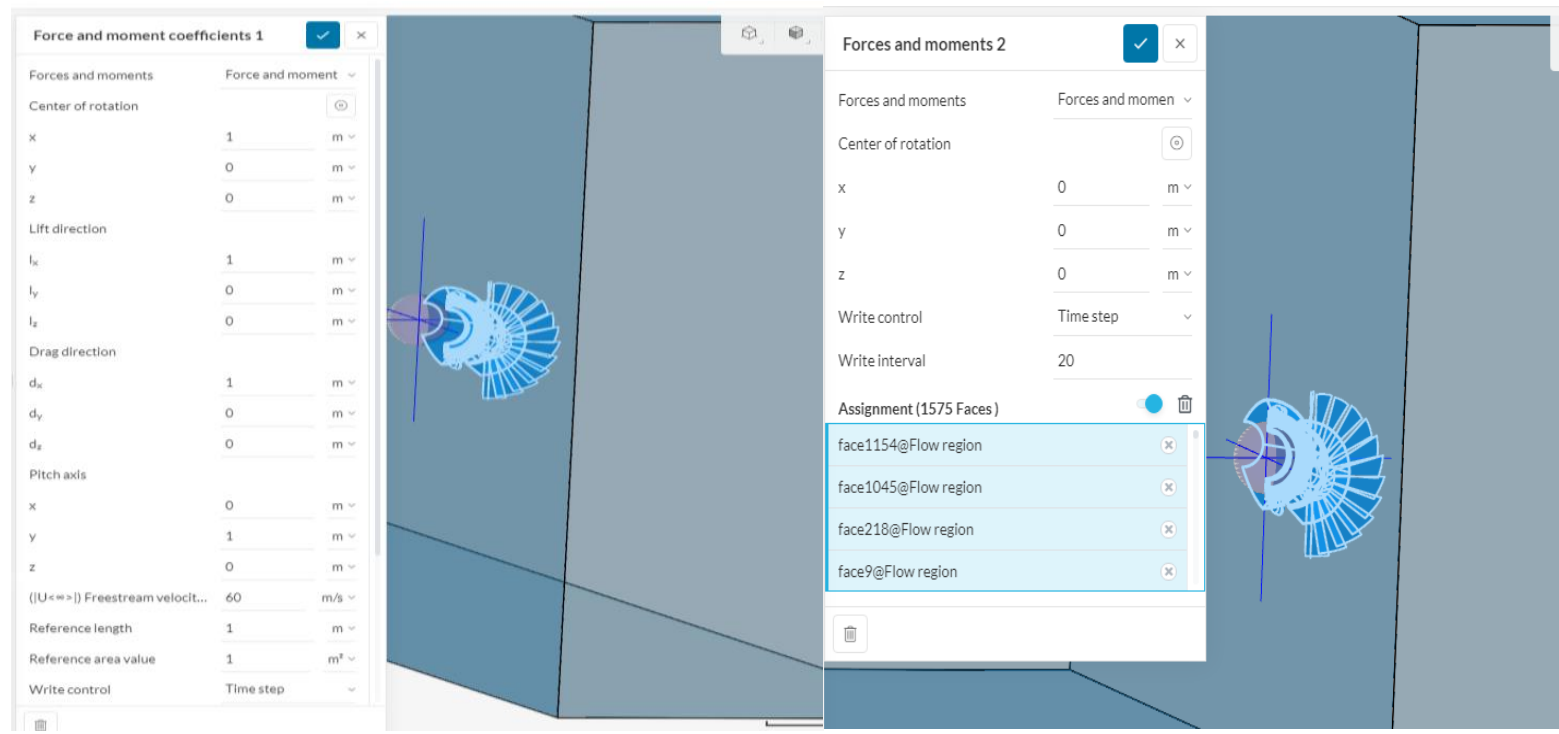

(a)

(b)

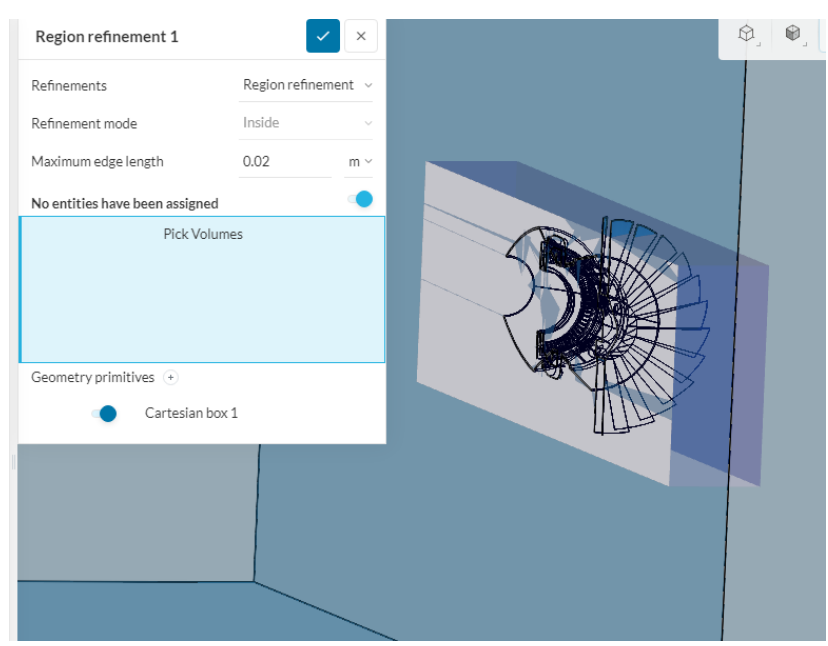

(c)

Figure 7: (A) Force and Moment Coefficients 1, (B) Force and Moment Coefficients 2, (C) Force and Moment Coefficients 1.

Post-Process Results - (Pressure Loss/Gain, Velocity \& Forces)

The CFD results in Figure 7 (a-c) show one half of the turbofan, because what happens on the one side will happen in the other half. Figure 8 shows the fluid particles as it passes through the turbofan engine and it is observed that the turbofan is not under too much stress due to the current condition of operation. It is also observed that, the particle traces of the air when the engine is running. Figure 8 (a-e) revealed the physical scenario of viscos flow trajectory as a function of the major parameters that impacts turbofan engine performance. These parameters are the flow velocity along the cutting plane of the fan air trajectory and velocity vector distribution of air molecules in the system during operation. 


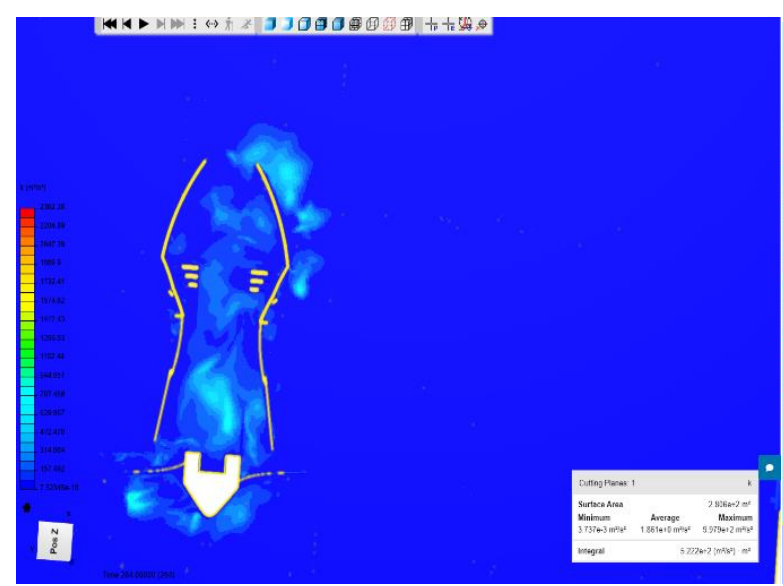

(a)

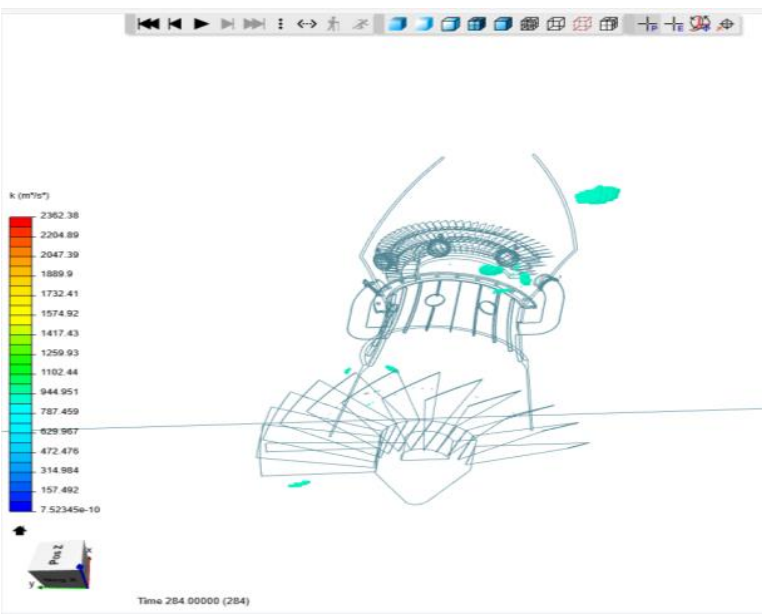

(c)

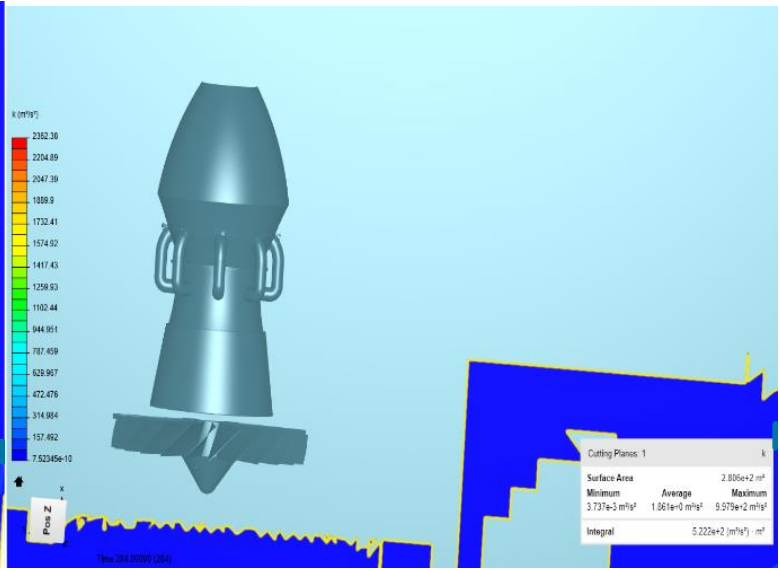

(b)

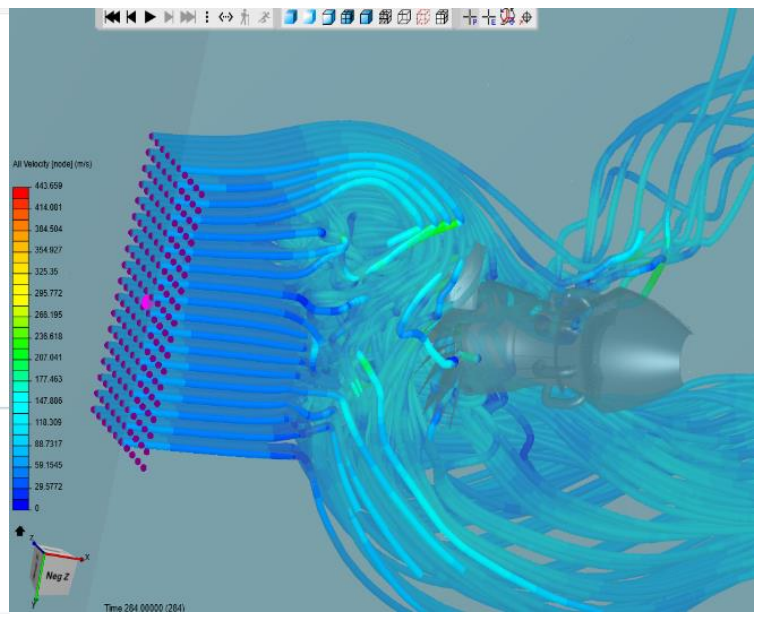

(d)

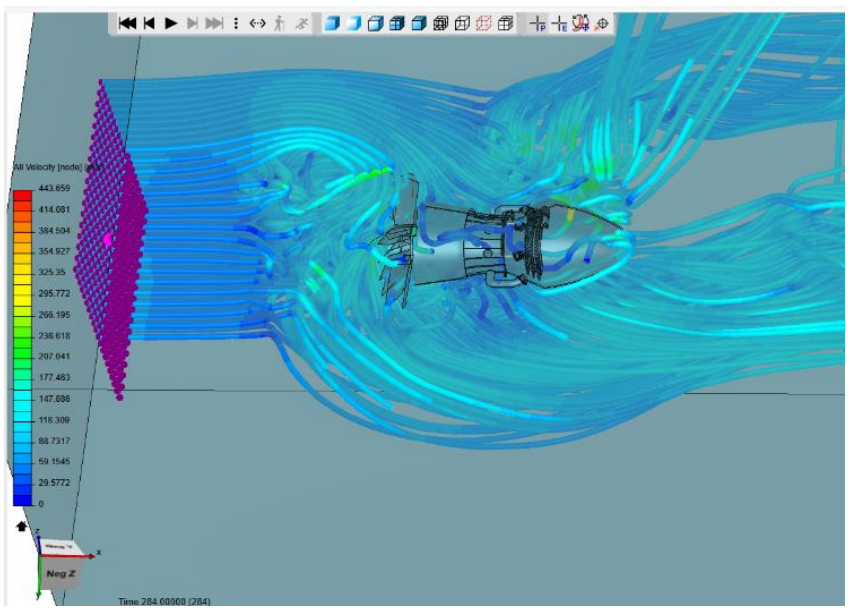

(e)

Figure 8: (a) Flow Cutting Plane, (b) Flow Cutting Plane, (c) Particle Traces: Velocity Vector (d) Particle Traces: Velocity Vector, (e) Particle Traces: Velocity Vector

The obtained results in Figure 8 revealed the design engine performance in CFD. It is revealed as shown in Figure 9 (a) that initially start operating at low engine speed with a very low inflow of air momentum in the system as shown in Figure 8 (a-b). As the mass flow of air increases in the system due to increase in speed in the fan, the mass flow of air in the 
system significantly increases and the speed and performance of the design turbofan engine systematically increases at optimal speed as shown in Figure 8 (c-e). It is observed as shown in Figure 8 (d-e) that at optimal speed, the system experiences high turbulences and the viscosity increases to keep the system more stable at optimal speed. The designed system is moving at high speed and the design turbofan engine is able to withstand the stress and strain generated by air and frictional resistant. There is no indication of material failure due to stress or strain at optimal speed as shown in Figure 8 (d-e). From the obtained results shown in Figure 8 the variation of velocity and time during operation can be analysed.

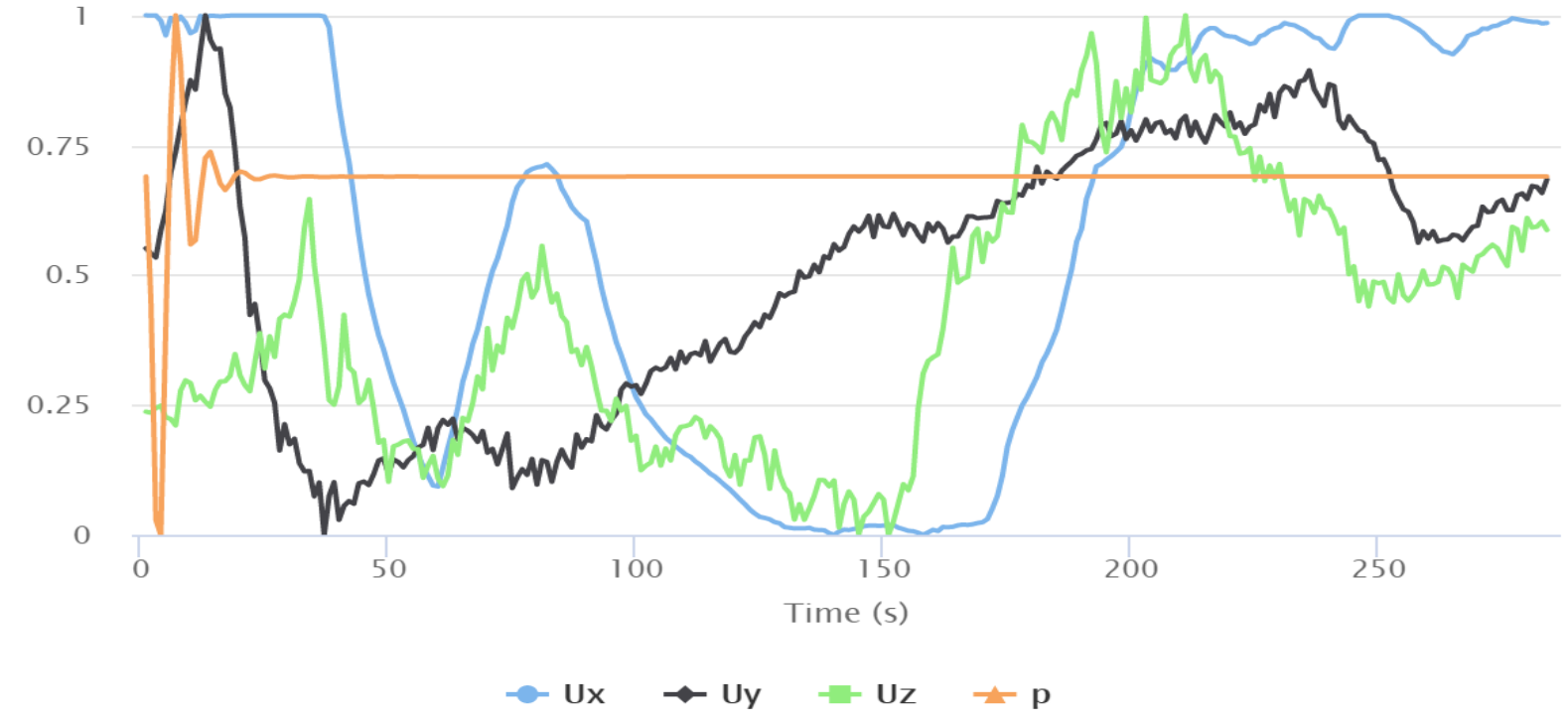

Figure 9: Outlet Velocity Vector against Time during Operation

The relationship between outlet velocity vectors against time is revealed as shown in Figure 9 for the different trajectory of the plane during operation. The velocity vector is the system dynamic forces that must be balanced to overcome the high turbulence experience of the system during operation at optimal operation. It is observed as shown in Fig.9 that the variation of the system outlet velocity vector changes rapidly in the varying planes of the turbofan engine (Ux, Uy, Uz and P). The flow trajectory along $\mathrm{P}$ initially varied between minimum and optimal point when the system initially started operating and at a time of 25 second the velocity stays constant throughout the system operation. Along the Ux plane, the velocity flow trajectory started at an optimal velocity of $1 \mathrm{~m} / \mathrm{s}$ and the velocity was kept constant for over a period of 50 second and the velocity vector decreases to $0.10 \mathrm{~m} / \mathrm{s}$ and experiences an exponential increased to 0.7 where the system immediately experiences as decrease to a minimum level of $0 \mathrm{~m} / \mathrm{s}$ and the system steadily increases to an optimal velocity of $1 \mathrm{~m} / \mathrm{s}$ and the velocity vector was stable at the optimal level throughout the system operation. The velocity vector trajectory along Uy revealed an increased inflow trajectory to an optimal level, which was accompanied by an exponential decay to a minimum velocity vector of $0 \mathrm{~m} / \mathrm{s}$ which was immediately followed by an exponential increase which was not steady or stable during operation. It was also observed that the flow velocity vector attained optimal level during operation. Along the direction of $\mathrm{Uz}$, the velocity vector increase from a lower level of 0.25 to an optimal level, which was accompanied by an exponential decay, which keeps fluctuating until the system attend an optimal range during operation. It could be concluded that the relationship between velocity, vector and time are not constant as their system is 
impacted by several dynamics forces which impacts turbulence and velocity vectors and this is impacted by the flow trajectory in the system during operation. This affects the forces in the system during operation as shown in Fig. 10

1.25

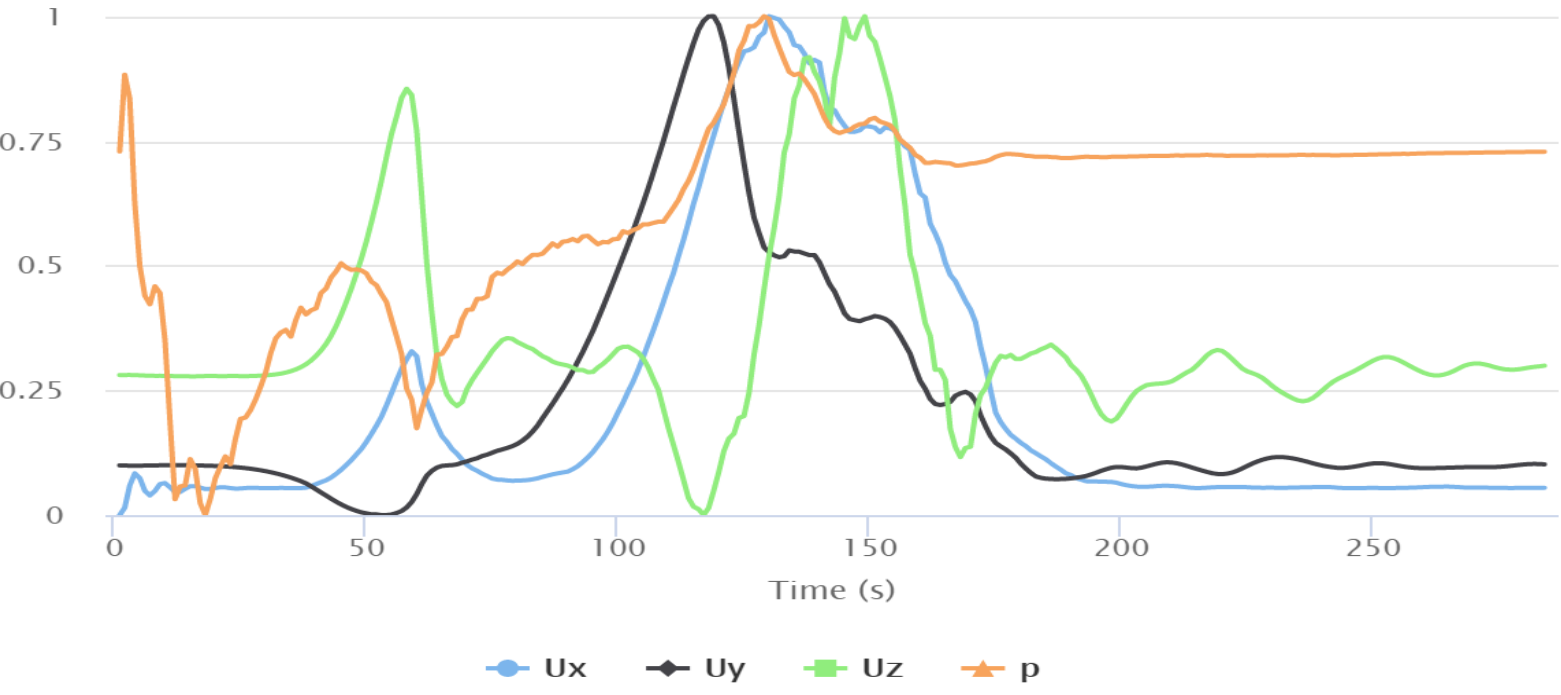

Highcharts.com

Figure 10: Force Vector against Time during operation

The results in Figure 10 revealed the relationship between force vectors against time during operation of the turbofan engine. It was shown that the variation between time and the force on vector was not uniform during the operation. It was shown that there are varying force vectors against time during along the Ux, Uy, Uz and P during operation. The force vector along $\mathrm{P}$ was revealed to have slightly increased from $0.75 \mathrm{kN}$ to o.80 $\mathrm{kN}$ before the force vector experienced an exponential decay to 10 seconds, which was accompanied by continuous increase that increases and decreases to an optimal range of $1 \mathrm{kN}$ before decreasing and moved with a constant force of $0.75 \mathrm{kN}$ throughout the period of operation. The flow trajectory of the system force along Ux and Uy showed an increased to an optimal force of $1 \mathrm{kN}$ and then increased and decreased steadily to a lower value that was kept constant throughout the period of operation. Along the direction of $\mathrm{Uz}$, it was shown that the forces experience a steady increase and decreases as time increases. The force was observed to increase and decrease to an optimal force of $1 \mathrm{kN}$ where a steady decrease was reported and the change in force was maintained almost steadily over a period of time as the system continues to operate. The reason for the change in force vector against time can be eluded due to the fact that there are several internal and external parameters that impact the performance of a turbofan engine during operation. These parameters are impacted by the mass flow of air through the turbofan engine. However, the mass flow rate of air through the turbofan engine is not constant and there are varying inflow angles that impact the flow momentum of the mass flow of air through the system. These are the main activities that impacts the force vector and outlet flow velocity during operation as shown in Figure 9 and Figure 10. This directly affects the pressure force, force of viscosity, porous force, pressure moment, viscous moment, and porous moment along the varying flow trajectory which are $\mathrm{X}, \mathrm{Y}$ and $\mathrm{Z}$ as shown in Figure 11. 


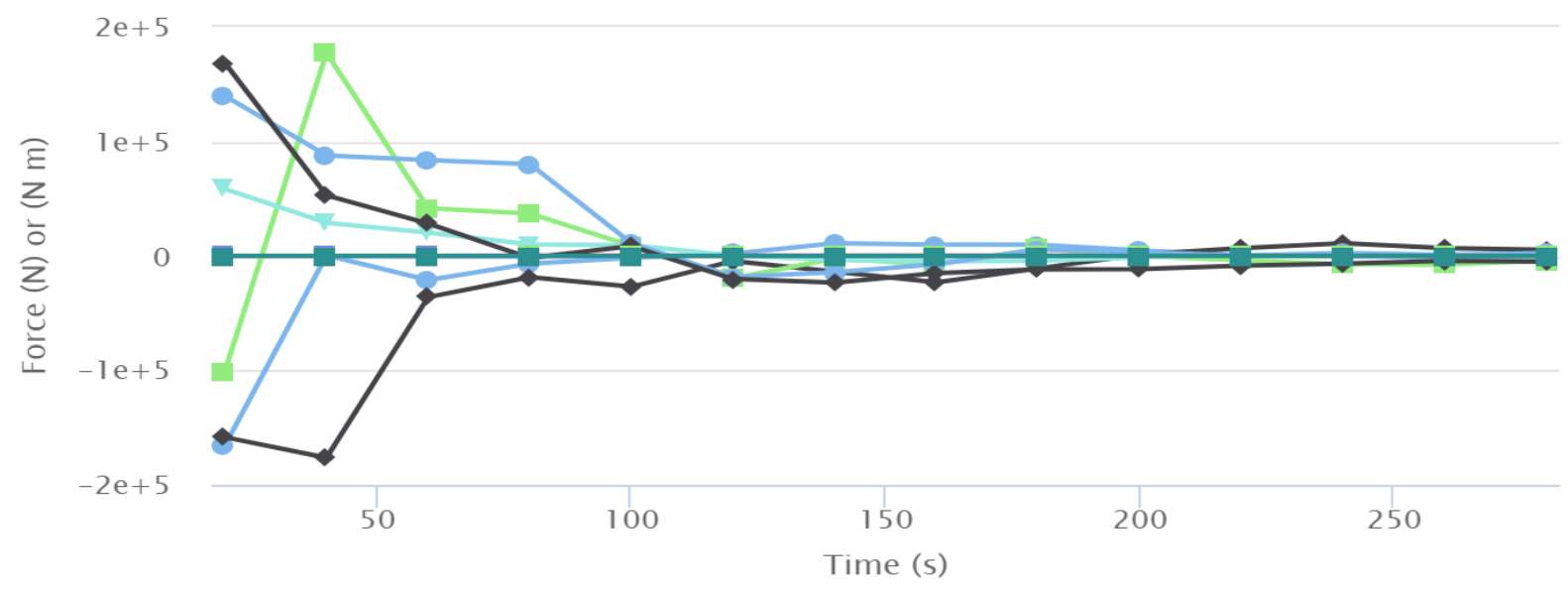

\begin{tabular}{|c|c|c|}
\hline & & \\
\hline 1 & & 5 \\
\hline$-V$ & Viscous force y & $-\infty$ \\
\hline Porous force $x$ & $\rightarrow$ Porous force y & $\mp$ Porous force $z$ \\
\hline$=$ Pressure moment $x$ & - - Pressure moment y & $\leadsto$ Pressure moment $z$ \\
\hline - Viscous moment $x$ & $=$ Viscous moment y & $\rightarrow$ Viscous moment $z$ \\
\hline - Porous moment $x$ & $\leadsto$ Porous moment y & - Porous moment \\
\hline
\end{tabular}

(a)

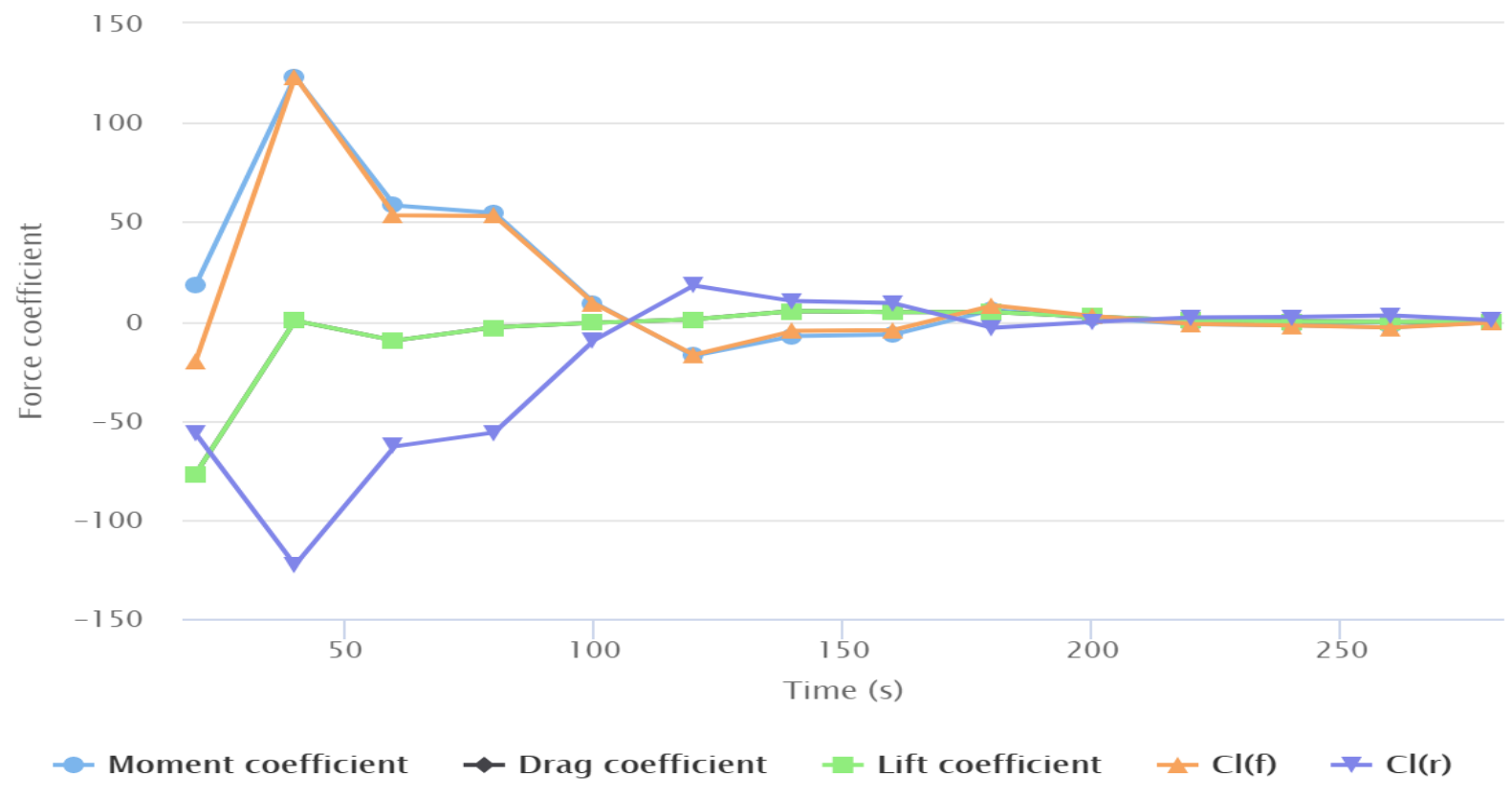

(b)

Figure 11: (A) Variation of Force on Pressure, Viscosity, Porous, and Momentum against Time (B) Variation of Force Coefficient against Time

The obtained results shown in Figure 11 (a-b) revealed how varying forces such as pressure, viscosity, porous, momentum coefficient, drag coefficient and lift coefficient have different variation when the turbofan engine started operating and these forces converges and impacted the stability of the turbofan engine during operation. It is observed from Figure 11(a) that the pressure force and the pressure momentum along the y plan initially increased during the initial operation of the turbofan to an optimal pressure and moment that was needed to keep the system more stable during 
operation. It was also observed along the x plane that the pressure force, viscous moment and pressure moment decreases when the turbofan started operating to a point where the system became constant and stable during operation. The graphs shown in Fig. 11(a-b) were gotten after running the turbofan engine during simulation. From the obtained results shown in Fig. 11 (a-b), it is shown that the forces in turbofan are not balanced during the initial period of operation. It is also shown that the system dynamic forces initially vary at different flow moment and pressure before the system attain stability during operation.

\section{CONCLUSION AND RECOMMENDATION}

The current study was aimed at modelling and simulates a novel design of a turbofan engine for optimal performance during operation. This was achieved byusing Autodesk Inventor software and Autodesk CFD software. The tool of finite element analysis was also used in modelling performance safety during optimal operation. A new turbofan engine was developed and the system performance was tested for proper operation. It was shown that the choice of material has a substantial impact on cost, manufacturing process, and the life cycle efficiency. Varying modelling and design analysis of fan, compressors, combustor, turbines, and nozzle were revealed by Autodesk Inventor software and Autodesk CFD software significantly impact design performance during operation. It was also revealed that a numerical analysis of the system mass flow rate on blade and inlet geometries impacts the performance of the turbofan engine and the system became more efficient during operation. The model had been built without the aid of proprietary data, thereby allowing the future integration of the engine model with the tip to tail "T2T" aircraft model previously developed by the authors. Special attention was also paid to the capturing of dynamic behavior. These transients not only increase model fidelity, but even more importantly, they reduce the occurrence of algebraic constraints, leading to increased simulation speed.

The particular setup used in this study seemed to lead to some good convergence, especially for the axial velocity and axial force as shown. Further investigations in this case can also be examined with a bigger background mesh box, to avoid contact of the airflow with the no-slip walls of the domain. Also, if more cores were available, an investigation of a similar system, with a compressor and a more complex turbine would give a better insight into the engine system's operation. It was also shown that, the thrust specific fuel consumption and specific thrust for a turbofan engine with the bypass ratio varying from 0 to 10 in steps of 5, compressor ratio varying from 16 to 40 in steps of 2, and bypass pressure ratio varying from 1 to 1.6 in steps of 05 . It was also shown that the T-s diagram of the turbofan engine with no afterburner. For each bypass and compressor ratio combination, the bypass pressure ratio, which yielded the maximum specific thrust, was obtained. The relationship that can be seen from all the obtained results shown that as the specific thrust increases, thrust specific fuel consumption increases and vice versa also as the total temperature at the inlet of the turbine increases. Higher fuel efficiency is better than having higher thrust because of the numerous amounts of times this engine will be operated for transportation.

\section{REFERENCES}

1. Parker, Khary I. and Guo, Ten-Heui. Development of a Turbofan Engine Simulation in a Graphical Simulation Environment. NASA Glenn Research Center. NASA/TM2003-212543.

2. Rahman, Naveed U. and Whidborne, James F., Real-Time Transient Three Spool Turbofan Engine Simulation: A Hybrid Approach. ASME Journal of Engineering for Gas Turbines and Power, 2009, Vol. 131, Issue 5, pp. 051602-1 - 051602-8. 
3. Al-Hamdan, Qusai Z. and Ebaid, Munzer S. Y. Modeling and Simulation of a Gas Turbine Engine for Power Generation. ASME Journal of Engineering for Gas Turbines and Power, 2006, Vol. 128, pp. 302 - 311.

4. Ainley, D.G., Mathieson, G.C.R. A Method of Performance Estimation for Axial Flow Turbines. Aeronautical Research Council Reports and Memoranda, 1957, R\&M Number 2974.

5. Cohen, H., Rogers, G.F.C., Saravanamuttoo, H.I.H. Gas Turbine Theory 4th Edition. 1996, Longman, London.

6. Jabbar, Ahmed Abdulhussein, et al. "DESIGN AND ANALYSIS OF GAS TURBINE ROTOR BLADE USINGFINITE ELEMENT METHOD." International Journal of Mechanical and Production, ISSN (P) (2014): 2249-6890. International Journal of Mechanical and Production Engineering Research and Development (IJMPERD) 4, 1, Feb 2014, 73-94

7. Kurzke, J. How to Get Component Maps for Aircraft Gas Turbine Performance Calculations. 1996, ASME paper 96-GT-164.

8. Cooke, James A, et al. Computational and experimental study of JP-8, a surrogate, and its components in counter flow diffusion flames. Proceedings of the Combustion Institute, 2005, Vol. 30, pp. 439 - 446.

9. OGUNWALE, OLUMUYIWA A., OT POPOOLA, and OO DAODU. "EXERGY ANALYSIS OF PROPANE-FUELLED VALVELESS PULSED COMBUSTOR." International Journal of Mechanical and Production Engineering Research and Development (IJMPERD) 10, 2, Apr 2020, 523-534

10. C. P. Mark and A. Selwyn, "Design and analysis of annular combustion chamber of a low bypass turbofan engine in a jet trainer aircraft," Propulsion and Power Research, vol. 5, no. 2, pp. 97-107, 2016.

11. J. D. Anderson Jr, Fundamentals of aerodynamics, McGraw-Hill Education, 2007.

12. SADHIQ, M., et al. "COMPUTATIONAL STUDY ON PERFORMANCE OF RAMJET ENGINE FOR VARIOUS MACH NUMBERS." International Journal of Mechanical and Production Engineering Research and Development (IJMPERD) 9, 6, Dec 2019, 475-484

13. E. Gamble, D. Terrell and R. DeFrancesco, "Nozzle selection and design criteria," in 40th AIAA/ASME/SAE/ASEE Joint Propulsion Conference and Exhibit, 2004.

14. L. E. Stitt, "Exhaust nozzles for propulsion systems with emphasis on supersonic cruise aircraft," NASA reference publications 1235, Ohio, 1990.

15. DIVYA, T., D. DAMODARA REDDY, and PHV SESHA TALPA SAI. "DESIGN OPTIMIZATION AND ANALYSIS OF COOLING FAN FOR AIR CRAFT ENGINE BY USING FE ANALYSIS." International Journal of Mechanical and Production Engineering Research and Development (IJMPERD) 2018, 182-188

16. S. Smith, “A simple correlation of turbine efficiency,” Journal of the Royal Aeronautical Society, vol. 69, 1965.

17. REDDY, SANDIRI SRIKANTH, and MANOJ KUMAR REDDY. "DESIGN OF ANNULAR COMBUSTION CHAMBER FOR A MICRO TURBOFAN ENGINE." International Journal of Mechanical and Production Engineering Research and Development (IJMPERD) 9, 6, Dec 2019, 747-754

18. AMINJAN, KIUMARS KHANI, POOYAN RAHMANIVAHID, and MILAD HEIDARI. "EFFECTS OF THERMODYNAMIC PARAMETERS ON PERFORMANCE OF GAS TURBINE CYCLE WITH REGENERATOR." International Journal of Mechanical and Production Engineering Research and Development (IJMPERD) 10, 3, Jun 2020, 7955-7964 